\title{
Anjos, demônios e transtornos mentais: os desafios do aconselhamento pastoral no contexto Pentecostal
}

\author{
Angels, demons and mental disorders: the challenges \\ of pastoral counseling in the Pentecostal context
}

\section{Ángeles, demonios y trastornos mentales: los desafíos de la consejería pastoral en el contexto pentecostal}

\author{
Nilton Eliseu Herbes* \\ Dainel da Silva Borges**
}

\begin{abstract}
RESUMO
Este artigo tem por objetivo analisar alguns dos principais fatores empíricos encontrados no axioma dos transtornos mentais. Ele busca expor a respeito das dificuldades do Aconselhamento Pastoral no contexto Pentecostal. Este trabalho é fruto de uma investigação bibliográfica e qualitativa disponível na internet nos últimos 16 anos. Como critérios de busca foi estabelecido dois filtros para esta seleção: o primeiro por meio da indicação do termo em questão, e o segundo por palavras que indicam a temática no resumo dos artigos. A partir da análise e leitura consultadas foi possível apontar que: no Brasil, existe um avanço dos transtornos mentais, ao mesmo tempo que uma eclosão Pentecostal. Isso lança questões a respeito de como podemos ter uma visão mais holística para as dificuldades inerentes às questões da saúde mental no Aconselhamento Pastoral no âmbito das comunidades Pentecostais. No contexto Pentecostal, há grandes dificuldades de a pessoa receber orientação eficaz quando o Aconselhamento se aproxima dos transtornos mentais. Olhando o ser humano de forma holística, a saúde do ser humano vai encontrar integralidade em todas as áreas da sua vida, seja ela física, espiritual e da sua alma.

Palavras-chave: Aconselhamento pastoral; pentecostal; transtornos mentais.
\end{abstract}

\begin{abstract}
This article aims to analyze some of the main empirical factors found in the axiom of mental disorders. It aims to expose about the difficulties of Pastoral Counseling in the Pentecostal context. This work is the result of a bibliographic and qualitative research available on the internet for the past 16 years. As search criteria, two filters were established for this selection: the first by indicating the term in question, and the second by words that indicate the theme in the summary of articles. From the analysis and reading consulted it was possible to point out that: in Brazil, there is an advance of mental disorders at the same time the Pentecostal movement in growing. This raises questions about how we can take a more holistic view of the difficulties inherent in mental health issues in the Pastoral Counselling and in the field of Pentecostal communities. In the Pentecostal context, there are great difficulties for a person to receive effective guidance when Christian Counseling coincides with mental disorders. Consequently, a person's well-being can find completeness in all capacities of his or her physical, mental, spiritual, and emotional health.

Keywords: Pastoral counseling; pentecostal; mental disorders.
\end{abstract}

* Doutor em Teologia pela Augustana-Hochschule, Neuendettelsau, Alemanha, e professor na Faculdade EST

** Bacharel em Teologia pela Universidade Luterana do Brasil. 


\begin{abstract}
RESUMEN
Este artículo tiene como objetivo analizar algunos de los principales factores empíricos encontrados en el axioma de los trastornos mentales. Busca exponer sobre las dificultades de la Consejería Pastoral en el contexto pentecostal. Este trabajo es el resultado de una investigación bibliográfica y cualitativa disponible en Internet durante los últimos 16 años. Como criterio de búsqueda se establecieron dos filtros para esta selección: el primero indicando el término en cuestión, y el segundo por palabras que indican el tema en el resumen de artículos. Del análisis y lectura consultados se pudo señalar que: en Brasil, hay un avance de los trastornos mentales, al mismo tiempo que un brote pentecostal. Esto plantea preguntas sobre cómo podemos tener una visión más holística de las dificultades inherentes a los problemas de salud mental en la Consejería Pastoral dentro de las comunidades pentecostales. En el contexto pentecostal, es muy difícil para una persona recibir una guía eficaz cuando el asesoramiento se acerca a los trastornos mentales. Mirando al ser humano de manera integral, la salud del ser humano encontrará integralidad en todos los ámbitos de su vida, ya sea el físico, el espiritual y el alma.
\end{abstract}

Palabras clave: Consejería pastoral; pentecostés; desordenes mentales.

\title{
Considerações iniciais
}

O axioma dos transtornos mentais são um grande desafio contemporâneo. No âmbito das comunidades cristãs pentecostais, ${ }^{1}$ por apresentarem um perfil socioeconômico baixo (STUMPF; HERBES, 2019, p. 234) e, muitas vezes, com falta de instrução adequada por parte de seus dirigentes, apresenta-se de modo controverso.

Segundo a análise de Howard J. Clinebell, "a poimênica e o Aconselhamento Pastoral contribuem para a permanente renovação da vitalidade de uma igreja [...]" (CLINEBELL, 2016, p. 14). Nessa senda, os conselheiros ou as conselheiras vão encontrar o enfrentamento dos mais diferentes assuntos, que perpassam de crises espirituais e falta de fé.

Nesse percurso, é possível encontrar pessoas que estão sofrendo de problemas psicossomáticos - transtornos mentais -, às vezes, decorrentes de depressão pela perda de um cônjuge, um filho ou estresse pós-traumático. Mas, também, no aconselhamento vão aparecer pessoas com questões orgânicas ou desequilíbrio químico.

Isso traz à tona a pergunta: como o conselheiro ou a conselheira identifica e encaminha para o tratamento especializado uma pessoa com transtorno

\footnotetext{
1 O movimento pentecostal espelha uma diversidade de grupos cristãos que incorporam, no sentido mais lato, experiências mais entusiásticas em sua homilia e vivência. O que os pentecostais têm em comum em seus ensinamentos, embora os pontos de vista sejam muitas vezes contrastantes, é experimentar o trabalho particular do Espírito Santo, o falar em línguas, curas e a expulsão de demônios como registrado, por exemplo, no Evangelho de Marcos 16.17-18. É importante pontuar que existem diferenças entre o movimento Pentecostal e Neopentecostal, esse último, de uma forma exacerbada, tem ênfase em curas, expulsão de demônios, muitas vezes, de formas teatrais e com o uso do mercantilismo religioso. Mas o carro chefe propulsor dessa corrente é a teologia da prosperidade material.
} 
mental? Posto isso, o objetivo geral deste artigo reside em problematizar as dificuldades enfrentadas no contexto pentecostal concernente identificação dos transtornos mentais, perpassando por uma breve análise da depressão.

À luz da pesquisa no campo da psicopatologia, percebe-se que há muitos aconselhadores e muitas aconselhadoras nas igrejas Pentecostais ${ }^{2}$, que, por desconhecimento, violam o direito à saúde mental e realização plena da pessoa humana.

Esse estudo traz à tona análises transpostas em pesquisas bibliográficas e de material de internet relevantes ao assunto. Como critérios de busca foram avaliados os trabalhos no período compreendido entre 2004 a 2020, sendo estabelecido também dois filtros para esta seleção: o primeiro por meio da indicação do termo em questão, e o segundo por palavras que indicam a temática no resumo dos artigos.

Por vezes, o aconselhador e a aconselhadora seja ministro e ministra ou não, se veem obrando com indivíduos que apresentam sintomas que se acredita serem possessão demoníaca e, até mesmo, negligência com o que é sacro. Porém, após a investigação científica, os sintomas da possessão espiritual são notavelmente semelhantes àqueles que caracterizam os transtornos mentais.

Dependendo do contexto cultural, não é raro que se interpretem como possessões pelo demônio, certos casos de dissociação, de epilepsia do lóbulo temporal, de esquizofrenia, de transtorno afetivo bipolar ou mesmo de alguns transtornos depressivos mais graves com sintomas psicóticos. Mas sem dúvida, os maiores clientes de espíritos e demônios continua sendo os histéricos, em suas mais variadas apresentações. (BALLONE, 2012, p. 186).

Exemplo disso, é a depressão, onde o ou a paciente se retrai do convívio social. Ou, no caso do transtorno bipolar, em que o ou a paciente experimenta mudanças drásticas no humor, são situações que a modo raso pode não ser percebido pelo conselheiro ou pela conselheira pentecostal e assim ser interpretado como possessão.

A falha na identificação de transtornos mentais pode trazer à luz anjos e demônios inexistentes. O bordão: "anjos, demônios e transtornos mentais", faz valência à ideia encontrada em alguns círculos pentecostais na antiguidade próxima e, até mesmo, em situações contemporâneas, que toda a sorte de males vem do pecado e de satanás e seus asseclas. É uma metáfora que traz à luz sobre a obscuridade da ignorância e do desconhecimento.

Falar do Pentecostalismo, transtornos mentais e sua vivência nas comunidades Pentecostais se torna um tema limitado no meio acadêmico, isso se dá pela falta de literatura nessa área de estudos. Sendo assim, muitas das informações desse artigo advêm da experiência de um de seus autores, por ser um pastor pentecostal, e de seu conhecimento de questão. 


\section{Os transtornos mentais e o pentecostalismo no Brasil}

Letícia Passos publicou recentemente (2019) que: "pesquisas contemporâneas mostram que $86 \%$ dos brasileiros têm algum transtorno mental e, que segundo especialistas, problemas de saúde mental costumam ser desencadeados pela pressão no ambiente de trabalho ou por situações afetivas da vida pessoal" (PASSOS, 2019). Certamente este é um índice alarmante.

Segundo Tiago Chagas, uma pesquisa mostra que 35\% dos cristãos sofrem ou já sofreram com doenças mentais. Além disso, a pesquisa também mostra um dado preocupante para a área do Aconselhamento Pastoral, mostrando que " $70 \%$ dos entrevistados entendem que as igrejas não têm estrutura para lidar com esse cenário” (CHAGAS, 2015). O que reflete a realidade de muitas comunidades cristãs pentecostais.

Juntamente com os transtornos mentais, surgem outras preocupações. A Organização Mundial da Saúde (OMS) divulgou uma pesquisa revelando que a taxa de suicídios a cada 100 mil habitantes aumentou $7 \%$ no Brasil, ao contrário do índice mundial, que caiu (FIGUEIREDO, 2019). Outro relatório da OMS afirma que no Brasil, a depressão atinge 11,5 milhões de pessoas (5,8\% da população), enquanto distúrbios relacionados à ansiedade afetam mais de 18,6 milhões de brasileiros ( $9,3 \%$ da população), um aumento de $18 \%$ se considerarmos o período entre 2005 e 2015, faz se constar que a maioria são mulheres (NAÇÕES UNIDAS NO BRASIL - OMS, 2017).

Essa dura realidade traz um desafio para a realidades das igrejas no contexto brasileiro. Maria Aparecida Antão publicou um artigo sobre como a igreja ou a comunidade de fé pode ajudar na causa dos que sofrem transtornos mentais:

Geralmente o que se observa é que antes de procurar um profissional especializado, muitos indivíduos que possuem vínculos religiosos e de fé buscam alívio para seu sofrimento dentro do âmbito das igrejas, congregações, grupos e outros espaços de prática da espiritualidade a que estejam vinculados. É neste momento que algo crucial pode ou não acontecer para favorecer ou adiar a intervenção adequada e necessária. (ANTÃO, 2018).

Dentro desse modelo, temos os poimênicos como first responders $3^{3}$. Normalmente, o primeiro a responder a situações de crise é o pastor ou pastora e isso de forma bem forte no Pentecostalismo. E, por confiarem na pessoa

\footnotetext{
Fazemos uso do termo em inglês que significa: primeiro respondedor, primeiro interventor, ou mais conhecido como socorrista, que é uma pessoa com treinamento que está entre os primeiros a chegar e fornecer assistência no local de uma emergência.
} 
aconselhadora, muitas vezes, quem procura apoio sai do encontro com o diagnóstico definido: “- falta de oração e leitura bíblica”, ou, “- isso é um ataque do inimigo!” Assim, entre anjos e demônios, a crise e a insegurança só se intensificam.

Segundo Everton Ricardo Bootz, "a angústia existencial é um dos principais problemas que o Aconselhamento Pastoral enfrenta” (BOOTZ, 2003, p. 13). Em vista disso, a desestruturação social, econômica, familiar e moral serve de supedâneo para estribar um elevado índice nas pesquisas hodiernas.

Não é o objetivo dessa pesquisa científica desvalidar o benefício espiritual da prática de oração e leitura bíblica para a espiritualidade e fortalecimento da pessoa humana. Mas, sim, corroborar para que à luz do Aconselhamento Pastoral saudável o indivíduo encontre plenitude.

A religião e espiritualidade são parte de todas as culturas e parte integrante do mais profundo anseio do ser humano ao longo da história. Encontrar - o sentido existencial -, talvez, seja o alvo, mais quisto do ser humano. Pois, a procura pelas dimensões espirituais e religiosas perpassam a natureza humana, do ser humano inquieto, instável e de uma personalidade complexa. Para Clinebell, "em cada novo meio ambiente, a igreja precisa encontrar maneiras novas de satisfazer as necessidades das pessoas atribuladas" (CLINEBELL, 2016, p. 16). Achando assim, o meio mais eficaz de auxiliar.

No Brasil contemporâneo há muitas pessoas vivendo a fé pentecostal. Segundo dados do censo do IBGE de 2010, no contexto brasileiro o pentecostalismo é o seguimento evangélico que mais cresce (IBGE, 2012). De acordo com Raquel de Paiva Mano, "A magnitude e o crescimento desse movimento no Brasil são impressionantes. No ano de 2000, o censo apontava que dos 26,2 milhões de evangélicos brasileiros, 17,7 milhões eram pentecostais, cerca de 67\% no total” (MANO, 2010, p. 60). A busca por soluções rápidas e práticas, algumas vezes até mágicas e místicas, fazem com que o Pentecostalismo tenha um crescimento exponencial, especialmente em um contexto socioeconômico como o brasileiro. O Instituto Humanitas Unisinos, assevera da seguinte forma: "Pentecostalismo cresce, sobretudo, na pobreza e na periferia das regiões metropolitanas. Seus fiéis concentram-se majoritariamente na base da pirâmide socioeconômica" (INSTITUTO HUMANITAS UNISINOS, 2010).

Da mesma forma, o médico psiquiatra Ballone, grifa: “Talvez, por conta da origem cristã-ocidental, miscigenada às crenças africanas, juntamente com aflição existencial que afeta boa parte da nossa população, o Brasil é um dos países onde se apela intensa e desesperadamente ao sobrenatural" (BALLONE, 2012, p. 155). Esse sobrenatural é encontrado, por vezes, de 
forma mais palpável no movimento pentecostal, onde anjos e demônios se manifestam nos momentos celebrativos e ritualísticos.

Para Miriam Cristina Rabelo, a experiência religiosa que o indivíduo participa no seu cotidiano, faz com que os reveses da sociedade contemporânea aflita e maltratada sejam enfrentados (RABELO, 1993). Ainda, nesta senda, o autor Ricardo Mariano ao analisar o fenômeno pentecostal faz a seguinte análise, acrescentando:

Os perfis socioeconômico e demográfico de pentecostais e protestantes são bastante distintos. Dados do último Censo revelam que a maioria dos pentecostais apresenta renda e escolaridade inferiores à média da população brasileira. Grande parte deles recebe até três salários mínimos e ocupa empregos domésticos, em geral modestos e precários, numa proporção bastante acima da média nacional. Em contraste, os protestantes históricos apresentam renda e escolaridade elevadas, ambas bem superiores à média brasileira, estando distribuídos mais nos níveis escolares de segundo grau, graduação e pós-graduação e nas faixas de renda entre seis e vinte salários mínimos. (MARIANO, 2004, p. 122).

Com oratórias vibrantes, apelo a orações e jejuns e, em alguns casos, ao escorregadio campo do misticismo - mágico-religiosos -, o Pentecostalismo ${ }^{4}$ ganha força pois encontra um solo fértil no Brasil, pois trata-se de um fenômeno religioso dinâmico e internamente muito diversificado, numa luta dualística constante entre anjos e demônios, entre o que é do mundo e o que é de Deus.

Ainda na perspectiva de Ballone, "a considerar a miséria vivencial do brasileiro, a carência cultural, material e de esperanças que experimentamos, não faltam bons motivos para sermos um povo cheio de fé" (BALLONE, 2012, p. 155). Hoje o pentecostalismo é uma força religiosa muito grande no Brasil e na América Latina, não há como negar os números das pesquisas sociais contemporâneas.

A grande maioria das comunidades pentecostais creem na mesma teologia que as igrejas protestantes históricas com relação a natureza de Deus. Porém, os pentecostais creem que o Espírito Santo empodera todos os aspectos de suas vidas, dando a eles habilidades miraculosas e dons espirituais e, em muitos casos, creem em uma forma mais acentuada de exorcismos. Paulo Augusto Seifert, aponta que: “em movimentos carismáticos, a possessão e o exorcismo são práticas 'comuns', fazendo parte do cotidiano religioso" (SEIFERT, 2013, p. 184).

4 É importante observar que o Pentecostalismo em geral é um movimento muito líquido, abrindo e fechando templos muito facilmente. Há, no entanto, muitos movimentos sérios e consolidados. 
Os pastores e as pastoras, em sua maioria, não possuem uma formação regular e um diploma universitário. Isso pode trazer à tona situações que devem ser refletidas metodologicamente ante aos desafios práticos que aparecem na atualidade na população brasileira. Historicamente, o diálogo entre a corrente pentecostal e o consultório de atendimento psicológico e psiquiátrico, de quando em quando, é muito complexo. A relação entre o sacro e o profano é áspera, pois muitos conselheiros cristãos e conselheiras cristãs não veem assuntos de saúde mental como algo que diz respeito ao ambiente sacro. Convém aqui destacar o que escreve Miriam de Jesus Ávila:

Como consequência, a igreja tem ido para o divã... Às vezes de forma aberta, esclarecida, convicta de que encontrará ajuda para seus dilemas, mas muitas vezes de forma discreta, temerosa e culpada por estar buscando um "auxílio mundano", talvez, para estes, porque a procura de ajuda especializada entre evangélicos e evangélicas parece enfrentar discriminação por parte de certos líderes/pastores e pastoras que acabam, em maior ou menor grau, influenciando negativamente ou até coibindo os membros de suas congregações de buscarem ajuda psicoterápica. (AVILA, 2017, p. 6).

Com esse horizonte podemos entender que esse assunto é muito complexo e estigmatizado, e, ao que tudo indica, muito negligenciado, especialmente no contexto pentecostal. Aparentemente o Aconselhamento Pastoral pentecostal, ocasionalmente, suprimem as emoções, e o intelecto olhando para o significado espiritual do significado, buscando anjos e demônios em situações que são aquém do ambiente sacro. Criando rivalidades entre o religioso e o psicológico. Num artigo recente de Nilton Eliseu Herbes e Miram Jesus e Ávila, onde discutem a relação e a dificuldade do aconselhamento pastoral e da psicologia temos os desafios para ambas os campos de atuação resumidos no final:

Tanto a Psicoterapia como o Aconselhamento Pastoral são tentativas humanas e, por isso, limitadas em auxiliar na resolução de todos os problemas e crises. Sendo assim, atitudes arrogantes e autossuficientes de lado a lado não irão contribuir na tarefa comum de auxiliar aqueles e aquelas que sofrem. Por outro lado, diluir diferenças e deixar de apontar de uma forma clara, crítica e objetiva as limitações, as possibilidades e as características de cada uma dessas disciplinas não é o melhor caminho a ser seguido. (HERBES; AVILA, 2020, p. 160).

No contexto pentecostal, às vezes, os problemas psicopatológicos são muito confundidos com temas religiosos e místicos, muito do que é dito como falta de atenção ao que diz respeito ao ambiente sagrado - oração, leitura bíblica, boa conduta, por exemplo - por vezes, é uma patologia psicológica, 
que não deve ser somente tratado no ambiente religioso, mas, também, com a ajuda de um especialista na área da psicologia ou psiquiatria.

\section{Aconselhamento a partir da Bíblia}

O drama cósmico que permeia o texto sagrado é supra importante para o Aconselhamento Pastoral, quando em um contexto interdisciplinar. Pois é entendido como um recurso terapêutico, vivo e intrínseco da integralidade da pessoa que professa a fé cristã.

A Igreja como ponto máximo para a pessoa cristã é o centro do propósito divino na terra, pois é nesse lugar que o finito se encontra com o infinito e de modo consequente, com aquelas pessoas que lhe representam. Nesse lugar, na perspectiva de Jamiel de Oliveira Lopes, "a igreja de Cristo tem a missão de edificar, admoestar e ajudar mutuamente os cristãos a permanecerem firmes na fé, evitando que os crentes tenham seus corações endurecidos pelo pecado (Hb 3.13; 10.25)" (LOPES, 2017, p. 274).

Segundo o mesmo autor existem várias razões pelas quais as pessoas buscam ajuda no aconselhamento; dentre elas, estão:

Crises diversas, depressão, ansiedade, preocupação, temor, fobias, transtornos emocionais, filhos envolvidos com alcoolismo e drogas, distúrbios sexuais (compulsão, perda de interesse pelo sexo etc.), conflitos nas relações interpessoais, dificuldades relacionadas à sexualidade, complicações na relação matrimonial, dificuldades nas relações familiares etc. (LOPES, 2017, p. 280).

Para esse autor, que demonstra a forma pentecostal de pensar, tais problemas devem ter uma abordagem bíblica, pois “as Escrituras devem ser usadas como um manual exclusivo em uma sessão de aconselhamento. Somente ela é capaz de resolver os problemas humanos na sua totalidade" (LOPES, 2017, p. 292).

Em contrapartida, Clinebell, em um de seus mais conhecidos livros no contexto brasileiro sobre aconselhamento, escreve que uso da Bíblia consiste em permitir que a sabedoria bíblica informe o processo, o espírito e os objetivos de relações de aconselhamento. Ela pode ser usada como consolo e fortalecimento às pessoas que estão em crise. Serve como meio de diagnose, ajuda a curar patologias espirituais e é usada para o crescimento espiritual (CLINEBELL, 2016, p. 120-121). Porém o autor ressalta que o uso literal da Bíblia se apresenta como um perigo para o aconselhamento. Afirmando inclusive que o modelo de Jay Adams é um mal exemplo do uso da Bíblia (CLINEBELL, 2016, p. 123). 
De acordo com João Henrique Stumpf e Nilton Eliseu Herbes, "a prioridade da poimênica, do Aconselhamento Pastoral no pentecostalismo está em melhorar o relacionamento do indivíduo com Deus, com vistas à salvação" (STUMPF; HERBES, 2019, p. 236). Tendo como base um aconselhamento numa hermenêutica literalista ou fundamentalista da Bíblia, no Pentecostalismo o aconselhamento pastoral consiste num chamado ao arrependimento, uma vez que a causa do sofrimento reside nos pecados individuais dos fiéis (STUMPF; HERBES, 2019, p. 235). Essa prática, no entanto, não abarca todos os poimênicos pentecostais. Há profissionais sérios e instruídos.

Lopes expõe seu conceito da seguinte forma: "o Aconselhamento Pastoral deve ser obra do Espírito Santo e feito com oração” (LOPES, 2017, p. 295). Onde percebemos que a ação do espírito, conjugado com a oração, é a forma de se fazer aconselhamento. No citado acima, fica claro que há divergências na forma de ver a função do aconselhamento no contexto pentecostal.

O pentecostalismo defende que apesar dos antagonismos sociais díspares entre o período bíblico e o contemporâneo, o cerne dos problemas são os mesmos - o sofrimento da pessoa humana - nas suas mais notáveis variáveis. As histórias de derrotas, angústias, aflições, vitórias e auxílios que emanam do texto sagrado, podem contribuir para a valoração do indivíduo hodierno. Pois, a Bíblia é um livro de muitas valências que perpassam a experiência humana através dos tempos. O teórico fundamentalista Jay Adams, sustenta a necessidade de a pessoa cristã utilizar basicamente a Bíblia como uma espécie de manual para a condução da vida. Com isso, Adams faz oposição à utilização de outras disciplinas e ciências humanas como parceiras no processo de cuidado e ajuda no aconselhamento pastoral (ADAMS, 1977, p. 9). A visão de Adams não é unânime em relação ao método do aconselhamento pastoral no âmbito do pentecostalismo, porém, com uma grande parcela de adeptos a forma de pensamento e prática. No entanto para usarmos a Bíblia no aconselhamento com um contexto psicopatológico temos que ter cuidado inerentes a situação.

Richard Dobbins possui uma postura que nos ajuda a entender como esse tipo de aconselhamento pode ser interpretado. Onde toda a ação parece ser de fora, ou seja, vinda da ação e do poder de Deus, no campo espiritual.

Quando assumimos esta postura espiritual, Cristo nos capacita a sermos um canal eficaz que liga o coração e a mente da pessoa aconselhada com o coração e a mente de Deus. Quando somos bem sucedidos nesta tarefa, os recursos ilimitados de Sua sabedoria, poder e graça incrementam sobrenaturalmente nosso treinamento e experiência no processo de aconselhamento, levando-o a outro patamar. Num ambiente espiritualmente enriquecido, o poder de Deus desfaz a escravidão dos aconselhados, cura suas 
mágoas e providencia a orientação que precisam para resolver outras dificuldades na vida. (DOBBINS, 2010, p. 9).

Com essa postura fica mais evidente que, de quando em quando, as coisas da ciência não possuem espaço nesta concepção. É axiomático que quando a dignidade da pessoa humana está posta em conflito, no tocante a sua fé em detrimento à ciência, a atenção tem que ser redobrada. O Aconselhamento Pastoral tem teorias, que em uma conversação visam a cura d'almas que passam por sofrimentos que afetam a vida espiritual da pessoa. No entanto, o Aconselhamento Pastoral tem dificuldades em ajudar pessoas no momento que o campo de ação não é mais a espiritualidade ou até mesmo algum problema da alma. Nesse sentido é importante os ou as responsáveis pelo aconselhamento entenderem as suas limitações, sua vulnerabilidade quanto ao desconhecido, supondo aqui que não haja nenhuma especialização destes na área da saúde mental.

No contexto das igrejas cristãs-Pentecostais-fundamentalistas, existe uma busca elevada para a santificação, que consiste em deixar as coisas do mundo e voltar-se para Deus. Estamos novamente na luta entre anjos e demônios. Desta forma, a pessoa fiel acumula derrotas por não conseguir suprir as demandas que a religião e a comunidade religiosa por conseguinte põe sobre o indivíduo. Não é de se olvidar que isso pode inflamar o sentimento mais íntimo da pessoa, fazendo com que ela não tenha uma espiritualidade digna, que para Lothar C. Hoch "é a maneira concreta que uma pessoa vive a fé cristã” (HOCH, 1983, p. 154).

Adams, afirma que: "pessoas rotuladas de neuróticas, psiconeuróticas e psicóticas", que faziam uso das casas de saúde mental, no estado de Illinois, EUA, estavam lá porque haviam fracassado em enfrentar os problemas da vida e, conseguinte, mantido o comportamento pecaminoso (ADAMS, 1977, p. 13).

Clinebell, mesmo sendo contra o uso fundamentalista da Bíblia no aconselhamento, vê a sua importância, nesse sentido:

Há diversas razões pelas quais é importante integrar os insights bíblicos com a prática desse ministério. Sendo a Bíblia a nascente de nossa tradição espiritual ocidental, permanecer em íntimo contato com ela pode ajudar a manter-nos enraizados em suas verdades fomentadoras de integralidade. Em segundo lugar, estar em contínuo diálogo com os insights bíblicos pode gerar, em quem presta assistência, atitudes que facilitam a cura e o crescimento. Em terceiro lugar, ao trabalhar com pessoas cujo background tornou as imagens bíblicas algo vivo para elas, imagens e verdades arquetípicas da Bíblia podem ser usadas como instrumentos de transformação criativas. Imagens, histórias e metáforas bíblicas vivas são formas de comunicar verdades profundas sobre a vida fazendo uso do 'cérebro direito'. Elas são um poder sustentador na vida de muitas pessoas socialmente 
desprovidas de poder que amam a Bíblia. Em quarto lugar, a sabedoria bíblica sobre a natureza da integralidade é necessária para criticar, corrigir e enriquecer compreensões psicológicas contemporâneas de integralidade. Em diversos aspectos importantes, a Bíblia contém uma compreensão de integralidade mais profunda e realista do que a psicologia humanística. (CLINEBELL, 2016, p. 50).

Nesse mesmo caminho, Bootz também escreve que "deve haver um equilíbrio em ambos os recursos: os espirituais e os oriundos das ciências humanas" (BOOTZ, 2003, p. 20). É importante que a Bíblia não seja usada de maneira legalista ou fundamentalista. Para esse autor, o aconselhamento cristão é saudável quando há o uso da Bíblia, mas também, o diálogo multidisciplinar, para que assim, a saúde da pessoa humana encontre integralidade.

De acordo com o escritor Paulo Dalgalarrondo, "a religião e a prática religiosa são fatores protetores de suicídio e transtornos mentais” (DALGALARRONDO, 2008, p. 80). Esse mesmo autor aponta que de uma forma mais global, há evidências de que:

Sujeitos que se envolvem com a vida e atividades religiosas, como frequência a cultos, orações e leitura de textos religiosos, e se consideram "pessoas mais religiosas" apresentam maior bem estar psicológico e menores prevalências de depressão, uso, abuso ou dependência de substâncias, ideação e comportamentos suicidas. (DALGALARRONDO, 2006, p. 177).

Farr Curlin, professor de medicina da Universidade de Chicago, nos Estados Unidos, mencionado por Mariana Bergel, acrescenta ao pensamento: "Grande parte dos médicos não encontra barreiras entre ciência e fé. A maioria dos profissionais americanos acredita que Deus intervém na saúde dos pacientes e, no entanto, continua a aplicar as últimas descobertas da ciência na sua prática” (BERGEL, 2007).

Vemos nas escrituras nos relatos que Jesus ministrou para pessoas que tinham, aparentemente, transtornos mentais. Não se deve olvidar que um terço do ministério de Jesus Cristo foi dispensado ao cuidado com a saúde dos necessitados. Em Mateus 4.23, o evangelista escreve: "E percorria Jesus toda a Galileia, ensinando nas sinagogas, pregando o evangelho do Reino e curando todas as enfermidades e males entre o povo." Em Mateus 9.35, o evangelista registra: "E Jesus ia passando por todas as cidades e povoados, ensinando nas sinagogas, pregando as boas novas do Reino e curando todas as enfermidades e doenças" (BÍBLIA SAGRADA, 2017). No mesmo diapasão, em Mateus 10.1, o evangelista anota: "Jesus, tendo chamado seus doze discípulos, deu-lhes poder para expulsar espíritos imundos e curar todas as doenças e males" (BÍBLIA SAGRADA, 2017). Entendemos ser esta a vontade 
de Jesus para com os aflitos, todavia as dificuldades inerentes ao assunto são claras e devem ser contextualizadas e atualizadas.

\section{Os transtornos mentais}

$\mathrm{Na}$ atualidade, a sociedade religiosa cristã tem enfrentado mudanças substantivas no campo religioso contemporâneo, especialmente no que tange as áreas emocionais, psicológicas e espirituais, relacionados ao ambiente do culto brasileiro. Pois, a decorrência de situações anormais em uma esfera maior, acaba se afunilando dentro do ambiente religioso em questão.

A Associação Nacional de Medicina do Trabalho (ANAMAT) em seu site escreve:

Conforme a Previdência Social, em 2017, episódios depressivos geraram 43,3 mil auxílios-doença, sendo a $10^{\mathrm{a}}$ doença com mais afastamentos. Já doenças classificadas como outros transtornos ansiosos também estão entre as que mais afastaram, na $15^{a}$ posição, com 28,9 mil casos. O transtorno depressivo recorrente apareceu na $21^{a}$ posição, com 20,7 mil auxílios. (ANAMAT, 2019).

A depressão está entre as principais causas de incapacidade no Brasil. Sendo o Brasil um país cristão, é inerente que muitos desses casos vão passar por aconselhamento em igrejas ou comunidades cristãs, pois esse é o contexto imediato de muitas pessoas. Elas buscam no aconselhador e na aconselhadora a ajuda para a incompletude humana e questões práticas da vida. Como conselheiros e conselheiras vamos encontrar desafios ante o perfil psicopatológico da sociedade atual. Um dos principais autores contemporâneos que estuda a psicopatologia, Dalgalarrondo define a psicopatologia da seguinte forma:

A psicopatologia, em acepção mais ampla, pode ser definida como o conjunto de conhecimentos referentes ao adoecimento mental do ser humano. É um conhecimento que se esforça por ser sistemático, elucidativo e desmistificante. Como conhecimento que visa ser científico, não inclui critérios de valor, nem aceita dogmas ou verdades a priori. (DALGALARRONDO, 2006, p. 27).

Os transtornos mentais são caracterizados por uma ampla variedade de sintomas que geram angústia ou incapacidade na vida pessoal, social e laboral da pessoa humana. Elas podem ser brandas, moderadas ou severas.

Usando a depressão a título de exemplo neste artigo, apuramos que ela afeta negativamente a maneira como a pessoa se sente, pensa e reage ao ambiente. Segundo a OMS, no Brasil, 5,8\% da população sofre com essa doença, que afeta um total de 11,5 milhões de brasileiros (WORLD 
HEALTH ORGANIZATION, 2017, p. 20). Para o teórico Gary Collins, a depressão pode ser agrupada em duas grandes categorias: genético-biológicas e psicológico-cognitivas. A depressão caracteriza-se por sentimentos como melancolia, tristeza, desencorajamento, além do mais, o indivíduo se vê sem esperanças, deprimido e não vê saída. Dessa forma, há um acentuado desinteresse em atividades sociais, o que contribuem negativamente à sua saúde (COLLINS, 2004, p. 124-27).

Para Dalgalarrondo, entre os principais sintomas da depressão estão: tristeza profunda sem motivo específico; ansiedade; angústia; apatia; desânimo; isolamento; redução ou incapacidade de sentir prazer/alegria em atividades que outrora despertavam boas sensações; indecisão; pessimismo; sentimento de inutilidade; sentimento de culpa; auto piedade; baixa autoestima; baixa libido; mudanças no apetite; perda ou ganho de peso não intencional; pensamentos negativos; dificuldade de concentração; dificuldade em tomar decisões; dificuldade para começar a fazer tarefas e terminar aquilo que já começou; alterações no sono (insônia, sono excessivo, ou ambos); pensamentos e/ou comportamentos suicidas e sintomas corporais, como dores, problemas digestivos e alterações nos batimentos cardíacos (DALGALARRONDO, 2008, p. 307-312).

Os transtornos depressivos podem levar a uma variedade de problemas físicos, emocionais e sociais, causando, inclusive, a diminuição da capacidade laboral e no relacionamento interpessoal. Convém salientar que os especialistas alertam que tecnologia e estilo de vida agitado da contemporaneidade podem desencadear a depressão.

A depressão deve ser tratada, existem vários tipos de tratamento com grande índice de eficácia. A consciência de que não é uma tertúlia de anjos e demônios deve ficar clara nesta questão. Sem ajuda de profissionais da psicologia, psiquiatras e outros profissionais de saúde mental, pode ser extremamente difícil para a pessoa lidar com a situação. O tratamento mais indicado pelos especialistas é o uso de medicamentos em conjunto com a psicoterapia. ${ }^{5}$

A gênese dos transtornos mentais é muito grande para ser abarcado nesse artigo, portanto o aconselhador ou a aconselhadora deve estar ciente das necessidades que se apresentam e buscar em literatura especializada um aprofundamento teórico no assunto ${ }^{6}$, para assim, reconhecer os sinais e poder dar uma melhor orientação prática para as pessoas de sua congregação.

\footnotetext{
Para mais informações sobre o tema: BRASIL. Ministério da Saúde. Ministério da Saúde. Depressão: causas, sintomas, tratamentos, diagnóstico e prevenção. 2020. Disponível em: < https://bit. ly/2RKk0by>. [Acesso em: 06 mar. 2020].

${ }^{6}$ Para mais informações, sugerimos acessar o sítio: MINISTÉRIO DA SAÚDE (org.). Saúde mental: o que é, doenças, tratamentos e direitos. Disponível em: <https://bit.ly/3acVExt>. [Acesso em: 06 mar. 2020].
} 
Há uma grande dificuldade de as pessoas religiosas fazerem uma terapêutica no campo da psicologia (LOPES, 2017, p. 8), talvez pelo passado, principalmente da psiquiatria. Dentro do meio cristão pentecostal, muitos religiosos ou religiosas são contra qualquer tipo de intervenção médica como psicólogos, psiquiatras e psicoterapeutas. Há, aparentemente, uma repulsa aos tratamentos mentais, pois há a crença que a prática religiosa é quem promove a cura.

\section{Considerações finais}

Este artigo teve por objetivo analisar alguns dos principais fatores empíricos encontrados no axioma dos transtornos mentais. A pesquisa alinhou os dados transversais recentes no Brasil sobre transtornos mentais e foi observado que perpassam a razoabilidade. Os resultados também apontaram que o Brasil é um país religioso, com uma grande eclosão no seguimento pentecostal diverso.

Isso posto, a pesquisa expôs a respeito das dificuldades do Aconselhamento Pastoral no contexto pentecostal fundamentalista. A partir da pesquisa foi possível apontar que: percebe-se, não poucas vezes, que a visão fundamentalista tolhe a pessoa humana de uma vida plena. Observa-se que há grandes dificuldades de o indivíduo receber orientação eficaz quando o Aconselhamento se aproxima dos transtornos mentais.

Foi verificado que é necessário refletir e dialogar mais com outras ciências, pois é necessário ter uma visão mais holística para as dificuldades inerentes às questões da saúde mental no Aconselhamento Pastoral na esfera das comunidades pentecostais. É premente que o conselheiro e a conselheira pentecostal tenham atenção e busquem indícios - insights ${ }^{7}$ - a respeito do que é transtorno mental e do que dificuldades espirituais inerentes à incompletude da pessoa humana nos seus aconselhamentos, para assim, o evangelho e os transtornos mentais não se confundirem.

Não podemos olvidar que a pessoa que busca aconselhamento tem o direito de uma vida plena física, mental e espiritual. Se o aconselhador e a aconselhadora não estiverem atentos aos problemas contemporâneos, isso pode causar danos espirituais, morais, psicológicos e sociais irreversíveis às pessoas aconselhadas.

O desafio que fica é pensar a partir de um contexto onde se levem mais a sério os aspectos psicopatológicos encontrados no Brasil e, consequente-

\footnotetext{
Traduzido do inglês - Insight é o entendimento de uma causa e efeito específicos dentro de um contexto específico. A capacidade de discernir a verdadeira natureza de uma situação.
} 
mente, nas comunidades pentecostais, para isso é necessário articular a práxis de um Aconselhamento Pastoral mais elástico, que conseguem compreender o indivíduo dentro do contexto maior (social, econômico, educacional, ...) do qual ele faz parte, equilibrando o cuidado espiritual, físico e psíquico da pessoa. Por fim, é preciso reconhecer definitivamente que transtornos mentais não é questão de anjos e demônios.

\section{Referências bibliográficas}

ADAMS, Jay. Conselheiro capaz: 6. ed. São Paulo: Fiel, 1977.

ANAMAT - Associação Nacional de Medicina. Transtornos mentais estão entre as maiores causas de afastamento do trabalho. 2019. Revista Proteção, São Paulo, 22 de abril de 2019. Disponível em: <https://www.anamt.org.br/portal/2019/04/22/transtornos-mentais-estao-entre-as-maiores-causas-de-afastamento-do-trabalho/>. [Acesso em: 02 set. 2020].

ANTÃO, Maria Aparecida. Como a igreja pode ajudar na causa dos que sofrem com doenças mentais. Ultimato, Viçosa, 10 de outubro de 2018. Disponível em: < https://www. ultimato.com.br/conteudo/como-a-igreja-pode-ajudar-na-causa-dos-que-sofrem-com-doencas-mentais>. [Acesso em: 02 set. 2020].

AVILA, Miriam de Jesus e. A igreja no divã: inquietações dos pastores e pastoras a respeito da psicologia. 2017. 84 f. Dissertação (Mestrado) - PPG Teologia, Faculdades EST, São Leopoldo, 2017. Disponível em: < http://dspace.est.edu.br:8000/xmlui/handle/BR-SIFE/826>. [Acesso em: 02 set. 2020].

BALLONE, Geraldo José. Ensaio de psiquiatria forense sobre o crime de Tarauacá. In: LEITE, Valdir Perazzo; BALLONE, Geraldo José; XANGAI, Juracy (Org.). Religião, crime e loucura: a tragédia do Tauari. Recife: Edições Bagaço, 2012.

BERGEL, Mariana. Fé influencia na Saúde. CRN-PB, 2007. Disponível em: < http:// www.crmpb.org.br/index.php?option=com_content\&amp; view =article\&amp;id $=21900$ :fe-influencia-na-saude\&amp;catid=46:artigos\&amp;Itemid=483 >. [Acesso em: 02 set. 2020]. BÍBLIA SAGRADA. Tradução de João Ferreira Almeida. Rio de Janeiro: Sociedade Bíblica do Brasil, 2017.

DOBBINS, Richard. O Aconselhamento Cristão Cristocêntrico: O papel do Espírito Santo no aconselhamento pastoral. Trad. Nadja Matta e Bruno Ferrari. Recursos Espirituais, nov. 2010. Springfield: Life Publishers International, 2010. Acesso: https://docplayer.com. br/8908376-Tema-desta-edicao-aconselhamento-e-cuidados-pastorais.html [Acesso em 02 set. 2020]

BOOTZ, Everton Ricardo. Consultei a Deus, ele me respondeu, e me livro de todos os temores: o uso de recursos espirituais no aconselhamento pastoral. São Leopoldo, 2003.

346 f. Disponível em: < http://www3.est.edu.br/biblioteca/btd/Textos/Doutor/bootz_er_ td34.pdf >. [Acesso em: 02 set. 2020].

BRASIL. Ministério da Saúde. Depressão: causas, sintomas, tratamentos, diagnóstico e prevenção. 2020. Disponível em: < https://www.saude.gov.br/saude-de-a-z/depressao>. 
[Acesso em: 02 set. 2020].

CHAGAS, Tiago. Estudo abrangente aponta que 35\% dos cristãos sofrem ou já sofreram com doenças mentais. Gospelmais, 2015. Disponível em: < https://noticias.gospelmais.com. br/estudo-35-cristaos-sofrem-doencas-mentais-79743.html >. [Acesso em: 21 jan. 2020].

CLINEBELL, Howard J. Aconselhamento pastoral: modelo centrado em libertação e crescimento. Trad. Walter Schlupp e Luís M. Sander. 6. ed. São Leopoldo: EST; Sinodal, 2016.

COLLINS, Gary R. Aconselhamento cristão: edição século 21. Trad. Lucília Marques Pereira da Silva. São Paulo: Vida Nova, 2004.

DALGALARRONDO, Paulo. Relações entre duas dimensões fundamentais da vida: saúde mental e religião. Revista Brasileira de Psiquiatria, São Paulo, v. 28, n. 3, p. 177178, 2006. Disponível em: < https://www.scielo.br/scielo.php?script=sci_arttext\&pid =S1516-44462006000300006>. [Acesso em: 27 jan. 2020].

DALGALARRONDO, Paulo. Religião, psicopatologia e saúde mental. Porto Alegre: Artmed, 2008.

FIGUEIREDO, Patrícia. Na contramão da tendência mundial, taxa de suicídio aumenta 7\% no Brasil em seis anos. Disponível em: <https://g1.globo.com/ciencia-e-saude/noticia/2019/09/10/na-contramao-da-tendencia-mundial-taxa-de-suicidio-aumenta-7percent-no-brasil-em-seis-anos.ghtml >. [Acesso em: 06 mar. 2020].

HERBES, Nilton Eliseu; AVILA, Miriam Jesus e. Psicologia e religião: um encontro inevitável. Pistis \& Praxis, Curitiba, v. 12, n. 1, p. 143-162, jan./abr. 2020.

HOCH, Lothar C. Espiritualidade e Personalidade. Estudos Teológicos, São Leopoldo, v. 23, n. 2, 1983. Disponível em: <http://ism.edu.br/periodicos/index.php/estudos_teologicos/ article/view/1295/1247 >. [Acesso em: 23 mar. 2020].

IBGE - Instituto Brasileiro de Geografia e Estatística. Censo 2010: número de católicos cai e aumenta o de evangélicos, espíritas e sem religião. 2012. Disponível em:<https:// censo2010.ibge.gov.br/noticias-censo.html? view=noticia\&amp;id=3\&amp;idnoticia=21-

70\&amp;busca =1\&amp;t=censo-2010-numero-catolicos-cai-aumenta-evangelicos-espiritas-sem-religiao >. [Acesso em: 03 mar. 2020].

INSTITUTO HUMANITAS UNISINOS. O pentecostalismo no Brasil, cem anos depois. Uma religião dos pobres. 2010. Disponível em: <https://metodista.br/faculdade-de-teologia//materiais-de-apoio/artigos/o-pentecostalismo-no-brasil-cem-anos-depois-uma-religiao-dos-pobres >. [Acesso em: 21 jan. 2020].

LOPES, Jamiel de Oliveira. Psicologia Pastoral: a ciência do comportamento humano como aliada ministerial. Rio de Janeiro: CPAD, 2017.

MANO, Raquel de Paiva. O sofrimento psíquico grave no contexto da religião protestante, pentecostal e neopentecostal: repercussões da religião na formação das crises do tipo psicótica. 2010. 192 f. Dissertação (Mestrado) - Curso de Psicologia, Psicologia Clínica e Cultura. Universidade de Brasília, Brasília, 2010. Disponível em: <https://repositorio.unb. $\mathrm{br} /$ handle $/ 10482 / 22775$ ? mode $=$ full $>$. [Acesso em: 21 jan. 2020].

MARIANO, Ricardo. Expansão pentecostal no Brasil: o caso da Igreja Universal. 2004. Disponível em: < https://www.scielo.br/pdf/ea/v18n52/a10v1852.pdf>. [Acesso em: 21 jan. 2020].

MINISTÉRIO DA SAÚDE. Saúde mental: o que é, doenças, tratamentos e direitos. Dispo- 
nível em: < https://bit.ly/2z7vzmQ >. [Acesso em: 06 mar. 2020].

PASSOS, Letícia. Pesquisa mostra que $86 \%$ dos brasileiros têm algum transtorno mental.

Veja, 31 de julho de 2019. Disponível em: <https://bit.ly/2XID126>. [Acesso em: 03 mar. 2020].

RABELO, Miriam Cristina. Religião e cura: algumas reflexões sobre a experiência religiosa das classes populares urbanas. Cadernos Saúde Pública, Rio de Janeiro, v. 9, n. 3, p. 316-325, 1993. Disponível em: < https://www.scielo.br/pdf/csp/v9n3/19.pdf> Acesso em: 22 jan. 2020.

SEIFERT, Paulo Augusto et al. Cultura Religiosa. Canoas: Ulbra, 2013.

STUMPF, João Henrique; HERBES, Nilton Eliseu. O cuidado diante das injustiças: uma análise sobre a práxis da poimênica e do aconselhamento pastoral na relação com o contexto latino-americano. Estudos Teológicos, São Leopoldo, v. 59, n. 1, p. 226-240, jan./jun. 2019.

WORLD HEALTH ORGANIZATION. Depression and Other Common Mental Disorders. 2017. Disponível em: < https://apps.who.int/iris/bitstream/handle/10665/254610/ WHO-MSD-MER-2017.2-eng.pdf;jsessionid=68B6AD219AAD60B1D12B075BD294B917?s equence $=1>$. [Acesso em: 23 mar. 2020].

Submetido em: 16-9-2020

Aceito em: 15-10-2020 